\title{
HEITOR FERREIRA LIMA E O NACIONAL-DESENVOLVIMENTISMO
}

\author{
Alexandre Juliani*
}

\begin{abstract}
Resumo: O objetivo central deste artigo é fazer uma reflexão crítica sobre os pressupostos teóricos e metodológicos utilizados na obra de Heitor Ferreira Lima. Pretendemos demonstrar, através da análise de alguns aspectos recorrentes em sua obra, a subordinação ao pensamento de Roberto Simonsen, principal líder da burguesia industrial do século XX. Assim, por meio da observação de evidências que descaracterizam uma análise integralmente marxista nos escritos de Lima, consideramos que seu pensamento fez parte do arcabouço ideológico da burguesia industrial em prol do nacional-desenvolvimentismo.
\end{abstract}

Palavras-chave: Heitor Ferreira Lima; Industrialização brasileira; Nacionaldesenvolvimentismo; Economia brasileira.

\section{Heitor Ferreira Lima and national-developmentalism}

Abstract: The main objective of this article is to make a critical reflection about the theoretical and methodological assumptions used in the work of Heitor Ferreira Lima. We intend to demonstrate, through the analysis of some recurrent aspects in his work, tying the thought of Roberto Simonsen, main leader of the industrial bourgeoisie of the twentieth century. Thus, by observing evidences that mischaracterize a wholly Marxist analysis in the writings of Lima, we consider that his thinking was part of the ideological framework of the industrial bourgeoisie in favor of national developmentalism.

Keywords: Heitor Ferreira Lima; Brazilian industrialization; National developmentalism; Brazilian economy.

* Universidade Estadual Paulista - Unesp, Marília-SP, Brasil. Email: alex.jul@hotmail.com. Recebido em: 30/11/2014 - Aceito em: 15/06/2015. 
$|182|$

Heitor Ferreira Lima e o nacional-desenvolvimentismo

\section{Heitor Ferreira Lima y el nacional-desarrollismo}

Resumen: El objetivo central de este artículo es hacer una reflexión crítica sobre las presuposiciones teóricas y metodológicas utilizadas en la obra de Heitor Ferreira Lima. Pretendemos demostrar, a través del análisis de algunos aspectos recurrentes en su obra, la subordinación al pensamiento de Roberto Simonsen, principal líder de la burguesía industrial del siglo XX. Así, a través de la observación de evidencias que descaracterizan un análisis integralmente marxista en los escritos de Lima, consideramos que su pensamiento hizo parte del marco ideológico de la burguesía industrial a favor del nacional-desarrollismo.

Palabras clave: Heitor Ferreira Lima; Industrialización brasileña; Nacionaldesarrollismo; Economía brasileña.

\section{Introdução}

Podemos dizer que a consolidação do capitalismo no Brasil representa o período de plena estruturação de suas forças produtivas, isto é, do desenvolvimento da industrialização. No século XIX ocorreram algumas iniciativas de incentivo e desenvolvimento à indústria brasileira, dentre as quais podemos citar os pioneiros empreendimentos de Mauá nos transportes ferroviários e a atuação econômica de Rui Barbosa como ministro da Fazenda durante o primeiro governo republicano.

Entretanto, somente no século XX o Brasil definitivamente concretizou seu processo de industrialização. Nesse período, podemos indicar como elementos determinantes para o desenvolvimento industrial a crise no abastecimento interno decorrente do primeiro conflito bélico mundial, o contexto político e econômico iniciado com a era Vargas e as atividades pioneiras de alguns personagens da industrialização paulista. Entre os pioneiros de nossa industrialização destacam-se as figuras de Antônio Proost Rodovalho, Francisco Matarazzo, os irmãos Jafet, Jorge Street, Morvan Dias de Figueiredo e, principalmente, o líder industrial Roberto Simonsen. Foi entre as décadas de 1930 e 1980 que o Brasil se tornou um país plenamente industrializado e capitalista. Assim sendo, devido à importância de tal período histórico para a constituição da realidade econômica brasileira, diferentes vertentes 
da intelectualidade nacional se debruçaram para compreender os traços essenciais que compuseram a conjuntura política e econômica desta época, nesse contexto se inserem os trabalhos de Heitor Ferreira Lima.

A partir de 1950 o referido autor foi responsável pela composição de vasto material sobre a historiografia econômica brasileira, de caráter pioneiro em muitos aspectos. Lima declarava ser adepto do materialismo histórico, e não há razão para duvidarmos disso, haja vista sua formação e trajetória de intensa militância no Partido Comunista do Brasil (PCB). Entretanto, apesar de seu empenho e dedicação em tentar realizar uma análise dos aspectos econômicos e industriais nacionais estruturados sobre os fundamentos teóricos e metodológicos do materialismo dialético, percebemos em seus escritos a ausência de uma efetiva discussão das relações sociais no processo de produção, desde a época colonial até a consolidação da industrialização. Além disso, este autor não apresenta uma abordagem crítica em relação às classes dirigentes, pelo contrário, deixa subentendido que algumas personalidades da então burguesia industrial emergente no Brasil foram responsáveis pela implementação do progresso, sendo este a causa primordial da melhoria nas condições de vida do proletariado.

Em agosto de 1937, a direção nacional do PCB, seguindo as orientações políticas da Internacional Comunista (IC), promoveu a organização de uma frente nacional em a favor da industrialização nacional e contra o imperialismo nazifascista. Desse modo, a burguesia industrial seria a "força motriz" da revolução brasileira, uma vez que, segundo as determinações teóricas dos "banguistas", se tratava de uma revolução democrático-burguesa. Heitor Ferreira Lima fazia parte do grupo de comunistas de São Paulo que se opôs à posição da direção nacional e via o proletariado como a única classe capaz de exercer tal função. Posteriormente, a partir da década de 1940 e, principalmente, após entrar para a Federação das Indústrias do Estado de São Paulo (FIESP), Lima adotou uma abordagem economicista em defesa de "uma particular forma de revolução burguesa, uma revolução passiva, como caracterizaria Gramsci, 
posto que foi conduzida por uma fração das classes dominantes, mas dotada de um programa, aquele da industrialização como rota da independência nacional" (DEL ROIO, 2014: 34).

Inicialmente, pretendemos apresentar de forma sucinta a trajetória política, intelectual e profissional de Heitor Ferreira Lima desde suas atividades sindicais, durante a década de 1920, até meados da década de 1960, quando começou a exercer a função de economista na FIESP. Em seguida, analisaremos o percurso de Roberto Simonsen como principal líder da burguesia industrial e a importância de seu pensamento para a constituição do arcabouço ideológico nacional-desenvolvimentista. Para finalizar, apresentaremos uma abordagem crítica do pensamento econômico de Lima, objetivando demonstrar a influência da obra de Simonsen em seus escritos.

\section{Formação intelectual e trajetória militante}

Heitor Ferreira Lima chegou ao Rio de Janeiro em 1922. Oriundo de Corumbá (Mato Grosso do Sul - MS) se transferiu para a antiga capital da República com o intuito de trabalhar e conseguir concluir seus estudos. Inicialmente, eram estas as suas pretensões, porém logo após conseguir o emprego de aprendiz de alfaiate, se envolveu com o movimento sindical e também ingressou no PCB. Desenvolveu com afinco suas atividades sindicais na União dos Alfaiates, chegando a ocupar o cargo de Secretário Geral deste órgão em 1927. Além das atividades sindicais, Lima mantinha intenso contato com os membros do Partido, inclusive Astrojildo Pereira ${ }^{1}$, tal contexto lhe permitiu ser escolhido como representante do PCB para ir a Moscou participar das comemorações do $10^{\circ}$ aniversário da Revolução Russa e estudar na Escola Leninista Internacional.

Permaneceu por três anos na Rússia, período de intensos estudos em que pôde consolidar sua formação intelectual: aprendeu

\footnotetext{
${ }^{1}$ Intelectual e militante do movimento operário e comunista. Foi um dos fundadores do PCB, exerceu o cargo de secretário-geral de 1922 até 1930.
} 
outros idiomas, estudou filosofia, história contemporânea e economia política, história do movimento operário internacional, história da revolução e do Partido Comunista russos, além de ter lido os textos de Marx e dos bolcheviques. A geração de Lima ficou conhecida como "jovens bolcheviques", depois de concluírem sua formação, muitos retornaram a seus países para dirigirem seus partidos. No caso de Lima, como Astrojildo Pereira havia sido destituído alguns meses antes de seu retorno, foi escolhido para assumir o cargo de Secretário Geral do PCB em uma conferência realizada com a finalidade de promover a reorganização do partido em janeiro de 1931. No entanto, sem base de sustentação política logo foi substituído (DEL ROIO, 2014).

A partir desse momento, Lima iniciou uma longa trajetória de militância, procurando sempre seguir as orientações que lhe eram atribuídas. Foi enviado ao Nordeste, acabou sendo preso e permaneceu encarcerado enquanto se desenrolava a Revolução Constitucionalista de 1932. Em uma conferência nacional do PCB no mês de julho de 1934, sob as determinações da interventora Inês Guralsky, representante da Internacional Comunista, Lima foi expulso do partido, porém mediante retratação e "autocrítica" ${ }^{2}$, sua expulsão foi anulada. Neste mesmo ano, foi detido e deportado para o Uruguai, retornando apenas em janeiro de 1935. Em agosto, foi enviado a São Paulo para ministrar um curso de formação política à militância comunista, o mesmo curso que havia desenvolvido e aplicado anteriormente no Rio de Janeiro.

Assim como a Aliança Nacional Libertadora (ANL), Lima e o PCB de São Paulo não participaram do levante de novembro de 1935. Depois deste episódio, a direção do PCB acabou ficando com Lauro Reginaldo da Rocha (Bangu), enquanto Lima ao lado de Tito Batini e outros militantes do Comitê Regional de São Paulo se opuseram a apoiar a linha que a Internacional Comunista (IC) passou a propagar em 1937 e que foi seguida pelo PCB

\footnotetext{
${ }^{2}$ Nessa ocasião, Lima e outros membros do partido foram acusados de sabotares, por não concordarem com a linha sindical imposta pelo Birô Político.
} 
(BATINI, 1991). A IC recomendava aos partidos comunistas para se organizarem em uma "frente única", estabelecendo elos com setores progressistas, inclusive a burguesia industrial, para compor uma chave antifascista. Segundo Lima (1982), os comunistas de São Paulo se colocaram contra esta linha de pensamento, pois entendiam que a burguesia nacional estava ligada ainda aos restos feudais e ao imperialismo, portanto a única classe capaz de conduzir a revolução até o fim seria o proletariado. Em maio de 1938, foi preso novamente, sendo libertado somente em agosto de 1939.

Até este momento, podemos ressaltar que a linha seguida pelos comunistas não atendia às necessidades da realidade brasileira, pois defendia a existência de um contexto revolucionário em nosso país. Tal distorção inerente às condições materiais e sociais foi reforçada pela intervenção da IC nas atuações do PCB que culminaram na constituição da ANL e na Intentona Comunista. Um dos elementos que favoreceu essa leitura distorcida do contexto nacional foi a intrusão do positivismo, assimilado principalmente pelos militares, na cultura de esquerda brasileira. A propagação do marxismo no Brasil ocorreu essencialmente pela difusão da revolução socialista na Rússia. Portanto, o marxismo soviético desenvolvido pelo partido se associou ao positivismo da vertente militar de esquerda por meio da adesão de Luís Carlos Prestes ao PCB.

Dessa maneira ocorreu uma fusão e síntese de grande alcance histórico no seio do movimento comunista do Brasil. O stalinismo predominante na IC e assimilado por um PCB portador de uma tradição cultural que o encontrava predisposto convergia com a cisão da esquerda militar que vislumbrava no marxismo staliniano um instrumento teórico-prático para radicalizar as esperanças contidas na sua originária convicção positivista, de uma ordem social fraterna, culta e orientada pela ciência (DEL ROIO, 2000: 82-3). 
Lima retornou ao Rio de Janeiro no final de dezembro de 1939. A cisão do grupo paulista em relação à direção nacional, liderada por Bangu, desdobrou-se em perseguições feitas pelo grupo dirigente do Comitê Central aos comunistas de São Paulo. Lima e outros, por meio do periódico A classe Operária, foram acusados de pertencer a um grupo trotskista que servia ao imperialismo e à polícia. $\mathrm{O}$ isolamento político e as perseguições resultaram em seu afastamento do partido. Desse modo, podemos dizer que se encerra a primeira fase da trajetória de Lima, tal momento é caracterizado pelo distanciamento do autor em relação ao PCB e também pelo encerramento das suas atividades de militância.

Em 1941, desligado do PCB, Lima transferiu-se definitivamente para São Paulo, trabalhou como jornalista e chegou a ser diretor da sucursal de O Observador Econômico. Em 1944, foi convidado por Roberto Simonsen para integrar o Conselho de Economia Industrial da FIESP. Na década de 1960, passou a atuar como economista no Departamento de Economia da FIESP e permaneceu nesta função até sua aposentadoria. Seu trabalho consistia basicamente em "estudar e dar parecer sobre projetos de lei apresentados no Congresso Nacional, referentes a assuntos econômicos e financeiros, preferencialmente, em que medida e forma atingiam os interesses da indústria, a fim de defendê-la" (LIMA, 1982: 279). Destarte, Lima passou a exercer o trabalho de intelectual, especialista em assuntos econômicos, cuja função era proteger os interesses da burguesia industrial.

Além das atividades de tradutor, jornalista e economista, também se dedicou ao estudo de nosso desenvolvimento econômico e industrial. Daí decorreu vultosa obra, pioneira em muitos aspectos, sobre a historiografia econômica brasileira. É interessante notar que a produção e edição da maior parte dos livros escritos por Ferreira Lima ocorreu no período em que esteve ligado à FIESP.

Em sua obra, tentou entender o desenvolvimento do nosso processo de produção, desde os seus albores na época colonial até a consolidação da industrialização em 1970. Os pressupostos 
teóricos utilizados em sua análise fazem parte "do seguro método de análise histórica e social, que é o marxismo" (LIMA, 1982: 130).

Portanto, a relevância do pensamento de Lima para a historiografia nacional é inegável, uma vez que se trata de uma tentativa de interpretação marxista da realidade brasileira que absorveu o pensamento nacional-desenvolvimentista. Além desta especificidade, há a peculiaridade referente à mudança radical em suas atividades, depois de um período de longa militância no PCB, passando a exercer a função de economista durante três décadas dentro da FIESP, maior órgão representativo do parque industrial nacional. Apesar de nunca ter deixado de se declarar marxista, a investigação de seus escritos demonstra que sua concepção, ou melhor, seus argumentos para tentar justificar a necessidade do processo de industrialização nacional sofreram forte influência do pensamento de Roberto Simonsen, principal líder da burguesia industrial paulista. Sendo assim, evidenciaremos alguns aspectos do pensamento econômico de Simonsen para compor nossa análise e ressaltar a ideologia progressista propagada pelos industriais durante o processo de industrialização.

\section{Simonsen e a ideologia nacional-desenvolvimentista}

Roberto Cochrane Simonsen, considerado o patrono da indústria moderna brasileira, nasceu em 1889 e morreu em 1948. Estudou engenharia, associou-se com alguns amigos e fundou a Companhia Construtora de Santos, em 1912. Foi nesta Companhia que Simonsen pôde refletir sobre as causas que originavam as desigualdades e desentendimentos entre patrões e empregados. O resultado de suas conjecturas sobre tal questão foi a implantação na indústria nacional dos "métodos da organização racional do trabalho e as comissões paritárias entre empregados e empregadores, para a solução dos conflitos que surgissem" (LIMA, 1976: 157). Em outros termos, Simonsen foi o responsável pela introdução no Brasil das práticas tayloristas de exploração 
do trabalho para extrair o máximo de rendimento da produção. É interessante notar como Lima parece ter considerado positivo aos trabalhadores a aplicação desse sistema:

[...] Roberto Simonsen deu ampla demonstração de sua capacidade profissional como engenheiro, levando a cabo obras de vulto, que requeriam aptidão, largos conhecimentos, qualidades de direção e dedicação ao trabalho. Renovou métodos de trabalho em suas atividades, como a introdução entre nós, do sistema racional de trabalho e legou valiosa experiência, efetuando construção de larga envergadura, em condições difíceis e variadas (LIMA, 1976: 160).

\section{Nesse sentido,}

A burguesia industrial que se vinha diferenciando de sua matriz social - a oligarquia do complexo cafeeiro -, organizava, a partir do confronto social no mundo fabril, um projeto hegemônico que misturava elementos do velho liberalismo manchesteriano, impulsor da revolução industrial inglesa, com o americanismo fordista que atualizava aquela visão num quadro de ampliação do controle da força de trabalho segundo os ditames do capital. Em pouco tempo, como elemento complementar constitutivo do fordismo, aqui, como alhures, optou-se pela organização taylorizada do processo produtivo, a ponta da modernidade até então (DEL ROIO, 2002: 12).

A burguesia industrial até a década de 1920, formada sob os princípios do liberalismo ortodoxo empregado desde a fundação da República, combateu veementemente a implantação de uma legislação trabalhista. Entretanto, houve uma mudança substancial nesse contexto em um curto período. Segundo Vianna (1976) em apenas dez anos ocorreu um deslocamento do ultraliberalismo ao corporativismo. 
[...] no curto espaço de uma década, a posição da burguesia industrial vai conhecer três grandes variações diante da legislação do trabalho. Nos anos pré-30, se caracterizará por extremado liberalismo, de tipo fordista, hostilizando as tentativas de formulação e/ou ampliação das leis sociais. Essa etapa se prolongará até os dois primeiros anos do governo provisório, mantendo nos industriais acesa a polêmica com o Estado, embora tenham abandonado a esta altura seu antigo discurso liberal. A segunda, modulação entre duas posições extremadas, será a da incorporação consentida da legislação por parte dos empresários. A alteração no seu comportamento não importará, contudo, em eliminação com os conflitos com o Estado, que persistem em questões de aplicação da lei e sobre sua oportunidade. A última corresponde à sua franca identificação com o chamado direito social, quando a estrutura corporativa sindical se constitui no projeto consensual das elites e classes dominantes (VIANNA, 1976: 288).

Segundo Leme (1978), entre 1919 e 1945 os industriais brasileiros desenvolveram um comportamento progressista no campo econômico, porém no campo social se mantêm conservadores. A classe patronal afirmava ser a indústria o principal fator de produção de riqueza em uma nação. Tal concepção de caráter progressista e positivista se colocava contra os interesses fisiocráticos da oligarquia agrária brasileira, que defendia o exclusivismo agrário. Assim, a partir da década de 1920 os industriais paulistas percebem a importância da organização classista para a defesa de seus interesses. O presidente da Associação Comercial de São Paulo declarava ser "fundamental a ideia de que as classes produtoras se organizassem cada vez mais, para a obtenção do reconhecimento de seus interesses por parte do Estado" (LEME, 1978: 15).

Nesse sentido, a fim de unir forças e promover a hegemonia da classe industrial, Simonsen foi um dos fundadores do Centro das 
Indústrias do Estado de São Paulo(CIESP), em 1928. Posteriormente, em 1934, foi eleito deputado da Assembleia Nacional Constituinte, exercendo o cargo até 1937. Durante o Estado Novo, participou do Conselho Nacional de Política Industrial e Comercial. Após 1945, combate intensamente o comunismo, idealizando a criação do Serviço Nacional de Aprendizagem Industrial (SENAI) e do Serviço Social da Indústria (SESI), com a finalidade de tentar aproximar patrões e empregados. Foi eleito senador em 1946 e apoiou incondicionalmente a cassação dos mandatos comunistas em 1947. Mesmo não sendo economista, Simonsen foi um dedicado estudioso da economia brasileira, numa época em que esta área do conhecimento não era praticada por especialistas (CORRÊA, 2011).

Todo grupo social, nascendo no terreno originário de uma função essencial do mundo da produção econômica, cria para si, ao mesmo tempo, organicamente, uma ou mais camadas de intelectuais que lhe dão homogeneidade e consciência da própria função, não apenas no campo econômico, mas também no social e político [...] Se não todos os empresários, pelo menos uma elite deles deve possuir a capacidade de organizar a sociedade em geral, em todo o seu complexo de organismo de serviços, até o organismo estatal, tendo em vista a necessidade de criar condições mais favoráveis à expansão da própria classe [...] (GRAMSCI, 1932: 15).

Devido a sua influência entre os industriais, podemos afirmar que o pensamento econômico de Simonsen representou em grande parte a ideologia progressista propagada pela burguesia industrial em defesa de seus interesses. Em 1929, a FIESP encarregou Simonsen de fazer um estudo sobre os desdobramentos da crise para o Brasil. Considerando que a FIESP já era a entidade de maior preponderância na elaboração de um programa econômico industrial e sua orientação econômica encontravase em consonância com os pressupostos econômicos de Roberto Simonsen, podemos dizer que o empresariado brasileiro de modo 
geral também se pautava "por um mesmo pensamento econômico: as orientações nas obras de Roberto Simonsen acham-se mais ou menos explícitas nas manifestações da Federação Industrial do Rio de Janeiro, da Confederação Industrial do Brasil" (LEME, 1978: 173).

A elaboração de um programa econômico para o Brasil, de acordo com as diretrizes estabelecidas pela FIESP em conformidade com os estudos deSimonsen, consubstanciou-se em estabelecer uma política financeira estável; elevar o poder aquisitivo da população por meio do aumento da produtividade; racionalizar a produção agrária; unir o desenvolvimento da lavoura ao da indústria e, por fim, estabelecer uma política comercial externa. Tais argumentos foram reforçados por Simonsen em 1943 no I Congresso Brasileiro de Economia ao discutir o contexto econômico criado pela Segunda Guerra Mundial.

Em face dessa problemática, isto é, das perspectivas e dilemas criados com a Segunda Guerra Mundial e a mobilização econômica do Brasil. Roberto Simonsen considerou que o setor privado não estava preparado para fazer face às novas exigências do capital, tecnologia, Know-how, capacidade de organização, liderança, etc. Por isso, as novas perspectivas de desenvolvimento econômico e, em especial, industrial, exigiam a formulação e utilização de novos instrumentos de ação, incluindo-se o planejamento e o pensamento técnico-cientifico (IANNI, 1977: 55).

De acordo com Maza (2004), as discussões sobre o planejamento emergem em um contexto histórico demarcado por dois elementos bem específicos: "a crise política interna, oriunda de uma 'série de problemas econômicos', e a 'reorganização da economia mundial' que, no final da Segunda Grande Guerra, 'obrigava as classes dominantes a se posicionarem sobre os rumos da economia"' (MAZA, 2004: 204). Em tal contexto, emerge o famoso debate travado por Simonsen e Gudin em torno da oposição entre planejamento e liberalismo. Esse debate iniciou- 
se a partir do projeto apresentado por Simonsen ao Conselho Nacional de Política Industrial e Comercial em 1944. Da correlação de forças da época decorre uma bifurcação sobre a postura econômica que deveria ser adotada no Brasil. Essencialmente, o caráter desse embate ainda se restringe à antiga dicotomia do pensamento econômico nacional: de um lado, temos uma corrente liberal que preservava em suas concepções um conteúdo fisiocrático e dependente do Brasil (gudinianos) e, de outro, uma burguesia emergente carregando a bandeira do planejamento econômico e do nacional-desenvolvimentismo como formas de elevar a renda nacional e atingir a independência econômica (desenvolvimentistas), este último representado principalmente pelo pensamento de Simonsen.

Em outras palavras, Simonsen entendia por planejamento econômico a necessidade de criar políticas econômicas governamentais para proporcionar condições adequadas ao desenvolvimento industrial. "Para tornar mais eficiente a defesa do seu projeto, Simonsen busca vincular os interesses da nação aos da indústria" (MAZA, 2004: 187). Não obstante a sua concepção hierarquizada do homem e da sociedade que observava não cultivar "a ilusão de uma possível igualdade social e material entre os homens. A hierarquia social, que se estabelece em função da capacidade dos valores individuais, nunca poderá desaparecer, em harmonia, aliás, com tudo quanto se observa na natureza" (SIMONSEN, 1973: 466).

Destarte, podemos dizer que Simonsen buscou defender a modernização nacional através de "mecanismos que não contemplavam a plena expressão dos direitos políticos das camadas populares. Portanto, parece-nos correto que seu caminho foi o de uma modernização conservadora que buscava o 'progresso' sem a chancela popular" (MAZA, 2004: 234). De modo geral, os elementos do pensamento econômico nacional-desenvolvimentista deste, que foi o principal líder da burguesia industrial no Brasil, foram incorporados pelos escritos de Lima a partir da década de 1940. 


\section{O pensamento econômico de Heitor Ferreira Lima}

O primeiro livro sobre história econômica escrito por Lima foi publicado em 1954 e abordava a industrialização paulista. Foi lançado em virtude da comemoração do IV centenário da fundação da cidade de São Paulo e recebeu o título de Evolução Industrial de São Paulo. Logo no início, o autor nos apresenta sua concepção de História, que, segundo ele, não deve ter um interesse meramente acadêmico. Ao contrário, examinando o passado de forma imparcial e perspicaz, encontraremos "experiências proveitosas, positivas ou negativas, que nos podem servir de lição modernamente, repetindo-a ou repelindo-a, conforme o caso, ou melhorando-a, para nos ajudar a encontrar a solução de vários problemas que nos preocupam presentemente" (LIMA, 1954: 101), isto é, a História tem um valor pragmático. Mas quem faz uso deste conhecimento? A resposta veio no livro Formação Industrial do Brasil (período colonial), publicado em 1961. Esta obra constitui um estudo econômico do nosso período colonial, o próprio título já sugere a existência de uma indústria em nosso contexto colonial, ou seja, implica a premissa do desenvolvimento do capitalismo desde os albores de nossa colonização. Caio Prado Jr., outro militante comunista, em História econômica do Brasil, de 1945, também apresentou uma visão análoga sobre essa questão. Lima começou o livro exaltando a figura de Simonsen, segundo ele, graças à

[...] inteligência e cultura que possuía, Roberto Simonsen soube colocar suas ideias em nível elevado e persuasivo [...] Daí que uma parte considerável dos pontos de vista preconizados atualmente pela CEPAL (Comissão Econômica para a América Latina) e por numerosos estudiosos da situação brasileira, guardem com elas extrema semelhança, chegando por vezes à identidade [...] (LIMA, 1961: 3).

Depois de ressaltar a importância das ideias econômicas de Simonsen, repetiu a mesma concepção sobre a História apresentada no livro de 1954, porém acrescentou: 
Não esqueçamos que consistindo a economia a infraestrutura da sociedade, é que determina a ação dos homens no campo político, administrativo e social em geral. É necessário, por conseguinte, estimular por todos os meios, os trabalhos que visam o estudo da História Econômica, pela importância que representa. Neste sentido, podem prestar ajuda de enorme relevância às entidades das classes patronais, às fundações e mesmo às grandes empresas, por meio de organizações que já possuem ou por outras que sejam criadas com essa finalidade (LIMA, 1961: 5-6).

Para Lima são as "classes patronais" que devem fazer uso do instrumental teórico produzido pelas pesquisas econômicas. Sendo assim, deixa entendido que a burguesia era mesmo a força motriz do desenvolvimento das forças produtivas. Tal posição é distinta a que ele mesmo, juntamente com o Comitê Regional de São Paulo, defendia em 1937. Entretanto, por hipótese, podemos cogitar que Lima absorveu uma característica da época que "foi a importância dada à história econômica conectada a certo senso comum de um marxismo positivista" (DEL ROIO, 2014: 31).

Ainda sobre o livro de 1954, quando Lima trata das atividades do industrial Jorge Street, podemos perceber a ausência de uma análise mais profunda das relações sociais no contexto fabril. O que Gramsci caracterizou como "americanismo e fordismo", ou seja, as atitudes dos industriais em "prol" da classe operária decorrem da

[...] necessidade imanente de chegar à organização de uma economia programática e que os diversos problemas examinados deveriam ser os elos da cadeia que marcam precisamente a passagem do velho individualismo econômico para a economia programática: esses problemas nascem das várias formas de resistência que o processo de desenvolvimento encontra em sua evolução (GRAMSCI, 1934: 241). 
Ao contrário de Gramsci, Lima concebe as adaptações estruturais realizadas nas fábricas para maior aproveitamento da energia psíquica e física dos operários como algo positivo. Para este autor, os empreendimentos de Jorge Street representam "uma fábrica de revolucionários" (LIMA, 1954: 175).

Em 1963, Lima publicou o livro Mauá e Roberto Simonsen, posteriormente é acrescentado a esta obra um estudo sobre Rui Barbosa, sendo publicada com o título de 3 industrialistas brasileiros: Mauá, Rui Barbosae Roberto Simonsen, em 1976. Através das biografias de Rui Barbosa, Visconde de Mauá e de Roberto Simonsen, o autor realizou um estudo do surto de industrialização de nossa economia desde o final do segundo império até os anos 1940 do século passado. O livro procurou apontar a industrialização como fator imprescindível para a independência econômica nacional e melhoria no padrão de vida do proletariado, mesmos argumentos defendidos por Simonsen. Do Imperialismo à Libertação Colonial foi publicado em 1965. Neste livro reafirmou sua crença na iniciativa beneficente da burguesia.

As transformações econômicas de profundidade parecem que estão mudando as atitudes das diversas classes sociais ante os problemas fundamentais de seus países, dando-lhe outra consciência, levandoas a assumir posições que antes não se esperavam delas. São as condições materiais determinando a mentalidade dos indivíduos. Dessa participação mais ativa da burguesia e de outras classes sociais nas revoluções de libertação nacional, bem como nas tarefas que tais revoluções devem cumprir, vem decorrendo seu caráter (LIMA, 1965: 148).

É interessante ressaltar que o livro foi publicado no ano seguinte ao Golpe Militar de $1964^{3}$. Além disso, a ausência de uma

${ }^{3}$ O livro faz uma análise da economia mundial entre 1890 e 1960, não há nenhuma referência sobre o Golpe Militar de 1964. Somente em 1982, ao escrever seu livro de memórias, Lima apresentou uma breve exposição 
discussão mais efetiva em relação às classes dominantes denota uma concepção proveniente de um marxismo incipiente.

No início da década de 1970, publicou seu último livro concomitantemente ao seu trabalho exercido na FIESP. Em História político-econômica e industrial do Brasil afirmou que "uma grave lacuna, certamente, será observada neste trabalho: a falta de referência ao papel do proletariado no processo histórico que estamos examinando" (LIMA, 1978: 20). Entretanto, tal omissão não faz parte apenas deste livro, mas de toda a sua obra.

Depois de "trinta e poucos anos de trabalho na FIESP" (LIMA, 1982: 282), em maio de 1975, pleiteou sua aposentadoria e encerrou suas atividades nessa instituição. Mesmo aposentado, continuou pesquisando, escrevendo e publicou, em colaboração com o Instituto Roberto Simonsen (entidade de promoções culturais da FIESP), o livro História do Pensamento Econômico no Brasil, em 1976. Neste trabalho fez um estudo sobre a evolução do nosso pensamento econômico desde os primórdios da economia portuguesa, durante a idade média, até o embate do pensamento econômico brasileiro travado entre os gudinianos e os desenvolvimentistas. O décimo segundo capítulo é dedicado a Simonsen, uma vez que para Lima:

[...] a corrente de pensamento econômico melhor adotada às nossas condições particulares emergiu inicialmente no primeiro pós-guerra, em decorrência do primeiro progresso industrial registrado na época, com a criação do Centro das Indústrias do Estado de São Paulo e o aparecimento de Roberto Simonsen, preconizando a industrialização, como meio de erguer o baixo padrão de vida da população e superar o retardamento material em que nos encontrávamos. Até aí, nosso crescimento tinha

abordando tal contexto. Em seu comentário, declarou o envolvimento de diretores da FIESP-CIESP no movimento que instaurou o "regime totalitário e repressivo" no Brasil na década de 1960. 
sido "para fora", isto é, em função do processo de exportação de produtos primários que realizávamos, devido ao papel periférico por nós desempenhado na economia mundial. Propugnando Simonsen por novas atividades para aumento da riqueza geral, pregava na prática o desenvolvimento "para dentro", buscando com isso uma transformação estrutural. Mais tarde, no segundo pós-guerra, a CEPAL amplia, aprofunda e estende as teses de Simonsen para toda a América Latina, rejeitando a obsoleta teoria da divisão internacional do trabalho, formulada nos países adiantados, mas sem aplicação em outras regiões e em condições históricas diferentes. Brotavam assim, novas concepções de desenvolvimento, provocando reações diversas, conforme os interesses em jogo. Era um modo diferente de encarar questões antes não resolvidas, com instrumental teórico até aí aceito quase que como um dogma (LIMA, 1978: 5).

Além de ressaltar de forma imprescindível a contribuição do pensamento econômico de Simonsen, tanto para o Brasil como para a CEPAL. O excerto acima evidencia o quanto Lima compartilhava da ideologia nacional-desenvolvimentista, cujos desdobramentos principais seriam a transformação estrutural produtiva, o aumento da "riqueza geral" e a superação do "retardo material". Ao tratar o desenvolvimento do processo de industrialização apenas com elementos econômicos, suprime os interesses antagônicos entre a burguesia e o proletariado, negligenciando a correlação de forças sociais que protagonizaram o processo de desenvolvimento industrial e, consequentemente, a consolidação do capitalismo no Brasil a partir da década de 1930.

\section{Considerações finais}

O processo de industrialização nacional representa o período de pleno desenvolvimento das forças capitalistas que ocorreu concomitantemente ao desenrolar da revolução burguesa. 
De acordo com Del Roio (1990), o período crítico da revolução burguesa nacional foi entre 1928 e 1935, momento de consolidação do modo "passivo" de desenvolvimento capitalista. Tal processo pode ser caracterizado quando as forças sociais antagônicas (classes subalternas) à determinada ordem social não conseguem impor mudanças significativas que levem à instauração de um novo poder, isto é, uma nova organização política e econômica. Entretanto, devido à pressão exercida pelas classes subalternas, as classes dominantes sentem-se obrigadas a fazer mínimas concessões em troca da manutenção da ordem vigente. Desse modo, ocorre uma reorganização das classes dominantes no bloco de poder enquanto se processa a incorporação de novos setores sociais.

Devido a peculiaridades no contexto brasileiro, as forças operárias foram conduzidas durante esse processo pelo corporativismo estatal aliado à burguesia industrial, configurando o oposto de uma revolução democrática burguesa em relação ao modelo francês, como analisaria Gramsci. Outro fator relevante desse processo é que a industrialização representou, em grande parte, uma necessidade imposta por condições extrínsecas e não por forças internas. A necessidade de suprir o abastecimento interrompido devido à primeira guerra mundial estimulou o primeiro surto industrial. Desse modo, podemos dizer que nossa industrialização ocorreu de forma improvisada, sem as devidas adequações de um planejamento prévio que pudesse realmente pensar as questões nacionais.

O PCB, fundado em março de 1922, tendo como secretário geral a figura de Astrojildo Pereira, tentou realizar uma leitura da situação nacional e, a partir daí, promover um projeto que visasse uma solução para a crise brasileira. Dentre as medidas colocadas em maturação pelo primeiro grupo dirigente do partido, cujo principal elo com a Internacional Comunista era Heitor Ferreira Lima, podemos mencionar a constituição do Bloco OperárioCamponês. Entretanto, esta política de alianças sociais, buscando a constituição de uma hegemonia com outras tendências do 
movimento operário, foi interrompida pela intervenção da IC no PCB.

Posteriormente, a partir da década de 1950, já afastado do PCB e integrando o grupo de economistas da FIESP, o ex-secretário geral do PCB, Heitor Ferreira Lima, ressaltou essa questão da ausência de planejamento econômico em seus livros. No entanto, a análise de seus escritos demonstra que este autor desenvolveu uma argumentação subordinada ao pensamento econômico do principal líder da burguesia industrial. Em suma, o modo como corroborou o pensamento econômico de Roberto Simonsen, a ausência de uma discussão efetiva das relações sociais de produção e do papel do proletariado nesse processo histórico, desdobrouse em uma abordagem economicista em defesa do nacionaldesenvolvimentismo e caracterizam Heitor Ferreira Lima, a partir dos anos 1940, mais como um intelectual orgânico da burguesia, do que um autor efetivamente marxista.

\section{Bibliografia}

BATINI, T. Memórias de um socialista congênito. Campinas, SP: Editora da Unicamp, 1991.

CORRÊA, M. L. Um estudo sobre o debate desenvolvimentista nas páginas de $\mathrm{O}$ Observador Econômico e Financeiro (1936 - 1954). SIMPÓSIO NACIONAL DE HISTÓRIA DA USP, 26, 2011, São Paulo. Anais eletrônicos... São Paulo: USP, 2011. Disponível em: <http://www.snh2011anpuh.org/site/ anaiscomplementres>. Acesso em: 22 mai. 2011.

DEL ROIO, M. T. A classe operária na revolução burguesa: a política de alianças do PCB: 1928-1935. Belo Horizonte: Oficina de Livros, 1990.

DEL ROIO, M. T. A teoria da revolução brasileira: tentativa de particularização de uma revolução burguesa em processo. In. DEL ROIO, M. T.; MORAES, J. Q. (Org.). História do marxismo 
no Brasil: Visões do Brasil. Campinas, SP: Editora da Unicamp, 2000.

DEL ROIO, M. T. Heitor Ferreira Lima. In. PERICÁS, L. B.; SECCO, L. F. (Org.). Intérpretes do Brasil: clássicos, rebeldes e renegados. São Paulo: Boitempo, 2014.

DEL ROIO, M. T. Os comunistas, a luta social e o marxismo (19201940). In. REIS FILHO, D. A.; RIDENTI, M. (Org.). História do marxismo no Brasil: partidos e organizações dos anos 20 aos 60. Campinas, SP: Editora da Unicamp, 2002.

GRAMSCI, A. [1932] Apontamentos e notas dispersas para um grupo de ensaios sobre a história dos intelectuais. In. Cadernos do cárcere. Vol 2. Rio de Janeiro: Civilização Brasileira, 2001.

GRAMSCI, A. [1934] Americanismo e Fordismo. In. Cadernos do cárcere. Vol 4. Rio de Janeiro: Civilização Brasileira, 2001.

IANNI, O. Estado e planejamento econômico no Brasil 1930-1970. Rio de Janeiro: Civilização Brasileira, 1977.

LIMA, H. F. 3 industrialistas brasileiros: Mauá, Rui Barbosa, Roberto Simonsen. São Paulo: Alfa-Omega, 1976.

Caminhos percorridos: memórias de militância. São Paulo: Brasiliense,1982.

. Do imperialismo à libertação colonial. Rio de Janeiro: Fundo de Cultura, 1965.

. Evolução industrial de São Paulo. São Paulo: Livraria Martins Editora S. A., 1954.

. Formação industrial do Brasil: período colonial. Rio de Janeiro: Fundo de Cultura, 1961.

. História do pensamento econômico no Brasil. 2. ed. São Paulo: Brasiliana, 1978.

. História político-econômica e industrial do Brasil. São Paulo: Companhia Editora Nacional, 1970. 
. Mauá e Roberto Simonsen. São Paulo: Egladit, 1963.

LEME, M. S. A ideologia dos industriais brasileiros (1919-1945). Petropólis: Vozes, 1978.

MAZA, F. O idealismo prático de Roberto Simonsen: ciência, tecnologia e indústria na construção da nação. São Paulo: Instituto Roberto Simonsen, 2004.

SIMONSEN, R. C. Evolução industrial do Brasil e outros estudos. 7 ed. São Paulo: Editora Nacional; Editora da USP, 1973.

VIANA, L. W. Liberalismo e sindicato no Brasil. Rio de Janeiro: Paz e Terra, 1976. 